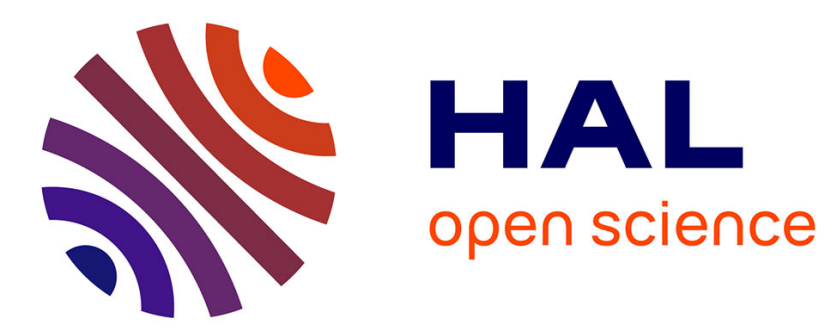

\title{
Spinal sensory circuits in motion
}

Urs Lucas Böhm, Claire Wyart

\section{To cite this version:}

Urs Lucas Böhm, Claire Wyart. Spinal sensory circuits in motion. Current Opinion in Neurobiology, 2016, 41, pp.38-43. 10.1016/j.conb.2016.07.007 . hal-01371943

\section{HAL Id: hal-01371943 \\ https://hal.sorbonne-universite.fr/hal-01371943}

Submitted on 26 Sep 2016

HAL is a multi-disciplinary open access archive for the deposit and dissemination of scientific research documents, whether they are published or not. The documents may come from teaching and research institutions in France or abroad, or from public or private research centers.
L'archive ouverte pluridisciplinaire HAL, est destinée au dépôt et à la diffusion de documents scientifiques de niveau recherche, publiés ou non, émanant des établissements d'enseignement et de recherche français ou étrangers, des laboratoires publics ou privés. 


\title{
Title
}

Spinal sensory circuits in motion

\section{Short title}

Sensory-motor integration in the spinal cord

\section{Authors}

Urs Lucas Böhm ${ }^{1,2,3,4}$ and Claire Wyart ${ }^{1,2,3,4, \#}$

\author{
Affiliations \\ ${ }^{1}$ Institut du Cerveau et de la Moelle Épinière, ${ }^{2}$ UPMC Univ. Paris 06, ${ }^{3}$ Inserm UMR S1127, \\ ${ }^{4}$ CNRS UMR 7225, Campus Hospitalier Pitié-Salpêtrière, 47 bld de l'Hôpital, 75013 Paris, \\ France \\ \#Correspondence: claire.wyart@icm-institute.org
}

\begin{abstract}
The role of sensory feedback in shaping locomotion has been long debated. Recent advances in genetics and behavior analysis revealed the importance of proprioceptive pathways in spinal circuits. The mechanisms underlying peripheral mechanosensation enabled to unravel the networks that feedback to spinal circuits in order to modulate locomotion. Sensory inputs to the vertebrate spinal cord were long thought to originate from the periphery. Recent studies challenge this view: GABAergic sensory neurons located within the spinal cord have been shown to relay mechanical and chemical information from the cerebrospinal fluid to motor circuits. Innovative approaches combining genetics, quantitative analysis of behavior and optogenetics now allow probing the contribution of these sensory feedback pathways to locomotion and recovery following spinal cord injury.
\end{abstract}

\section{Highlights}

- Main channels underlying mechanosensory responses have been identified in dorsal root ganglia

- GABAergic sensory neurons were recently identified as chemo- and mechanoceptors within the vertebrate spinal cord

- Proprioceptive pathways shaping locomotion appear distributed and multimodal 


\section{Keywords}

proprioception, locomotion, dorsal root ganglia, cerebrospinal fluid-contacting neurons

\section{Introduction}

Locomotion is generated by the oscillatory activity of motor neurons driven by groups of local interneurons in the spinal cord [1]. These premotor networks do not rely on sensory feedback to generate the basic locomotor rhythm as the isolated spinal cord can oscillate without any peripheral input in many species [2]. Nonetheless, in moving animals, there is evidence that sensory feedback provides strong modulation of locomotion and is critical for its proper function. In particular, excitation from peripheral afferents can initiate locomotion [3] as well as reset the oscillatory cycle [4]. Yet, the technical challenges that arise from selectively targeting and manipulating sensory pathways during ongoing locomotion make it difficult to probe the contribution of sensory feedback to natural locomotion. The recent discoveries of new channels and selective markers of sensory cells made it possible to map new pathways and investigate their functions. Here we discuss the latest work on the mechanisms and relevance of peripheral mechanosensory feedback for shaping motor output. In addition, we introduce the recent discovery that cerebrospinal fluid-contacting neurons (CSF-cNs) constitute a new class of GABAergic sensory neurons located within the spinal cord.

\section{Peripheral sensory neurons}

In the peripheral nervous system, dorsal root ganglia (DRG) are the primary entry point for somatic sensation in vertebrates. Temperature, pain, itch and touch but also proprioceptive signals like muscle contraction and load are relayed by DRG excitatory afferents to spinal circuits where they are processed (Fig. 1). These diverse signals are carried by different subclasses of DRG types. The sensory diversity of different DRG neurons primarily results from the differential expression of channels and receptors that mediate the different stimuli [5]. While peripheral sensory neurons mediate many different types of sensory inputs such as temperature, pain, itch and chemical irritants, the most relevant for locomotion is mechanical feedback from muscle and skin.

DRG subtypes have mainly been characterized based on their innervation pattern, electrophysiological properties and responsiveness [5]. The identification of genetic markers to label some of the subclasses such as parvalbumin for proprioceptive DRGs [6,7] has been key 
to understand the properties and functions of proprioceptive neurons. Recent efforts using single cell RNA sequencing made it possible to divide neuronal subtypes based on their gene expression profiles and provide a more comprehensive and unbiased classification. However, the exact number of subtypes and their functional characteristics remains to be established $[8,9]$.

A recent body of work identified Piezo2 as the main channel responsible for proprioception and touch response. The initial characterization of Piezo2 revealed expression in mouse DRG neurons [10]. Soon after, the channel was determined to be involved in vertebrate touch response in vivo in zebrafish. Knocking down piezo2b in zebrafish larvae leads to a loss of light touch but not nociceptive mechanosensation due to a loss of function in touch sensitive neurons [11]. Several studies performed since by the Patapoutian group established Piezo2 as the main channel to transduce touch response in mammals as well. Merkel cells, which are important for light touch sensation in mammals [12,13], rely on Piezo2 to be touch sensitive [14]. In addition to Merkel cells, Piezo2 is also necessary in A $\beta$ fibers which are relaying the light touch response from Merkel cells to the spinal cord. This dual role is likely the reason why only mice lacking Piezo2 in both Merkel cells and A $\beta$ fibers show strong deficits in their touch response [15]. Functionally relevant Piezo2 in Merkel cells and $A \beta$ fibers suggests a two-receptor site model for light touch where Piezo2 in Merkel cells is responsible for the static phase and Piezo2 in A $\beta$ fibers is responsible for the dynamic phase of the response [15]. Interestingly, similar to the observations made in zebrafish, mechanosensation in nociceptive C-fibers remained unchanged in the Piezo2 conditional knockout mice (Piezo2 ${ }^{\mathrm{CKO}}$ ), indicating that another yet unidentified channel is responsible for noxious mechanical stimuli.

In addition to mediating light touch response, Piezo2 is also the main mechanosensitive channel underlying proprioception, both in muscle spindles and Golgi tendon organs (GTO) [16]. In response to mechanical stimulation, parvalbumin-positive $\left(\mathrm{PV}^{+}\right)$proprioceptive neurons [6,7] lose their predominant rapidly adapting mechanical response in Piezo2 ${ }^{\mathrm{CKO}}$ while the less common intermediately adapting currents remained [16]. Consequently $\mathrm{PV}^{+} \mathrm{Piezo}^{\mathrm{CKO}} \mathrm{DRGs}$ are unresponsive to muscle stretch and Piezo2 ${ }^{\mathrm{CKO}}$ mice have marked limb coordination deficits [16]. It should be mentioned that some of the rare touch sensitive neurons were not explicitly tested in Piezo2 ${ }^{\mathrm{CKO}}$ mice, leaving the possibility of Piezo2 independent mechanosensitive neurons. Also, in neither of these studies, eliminating Piezo2 abolished all mechanicallyactivated currents $[15,17]$. These observations suggest that there are probably additional 
channels mediating mechanosensation. Furthermore, Piezo2 likely acts in concert with other molecular partners to tune its response in different cell types [18]. Nonetheless, during the last few years Piezo2 emerged as the main channel underlying mechanosensation in DRG neurons.

To what extend proprioceptive feedback contributes to locomotion has long been a debate in the spinal cord field [19]. Recently Akay et al. addressed this question in a mutant mouse model that lacks muscle spindle [20]. Mice lacking functional muscle spindle showed specific impairments in the timing of ankle flexor activity. Interestingly, this impairment was much more severe during swimming where proprioceptive feedback from GTO plays less of a role as the gravitational load is reduced. These results indicate that muscle spindles and GTO provide both distinct and redundant feedback when regulating muscle activity.

Proprioceptive feedback from muscle spindle and GTO is not the only source of sensory input shaping limb movement. Recent work also highlighted the importance of cutaneous feedback in grasping and locomotion $[21,22]$. Retinoid-related orphan receptor $(R O R)$ alpha positive interneurons were shown to receive inputs from both light touch responsive afferents and corticospinal pathways, likely integrating touch sensation and cortical commands [22]. Ablation of ROR alpha reduced the light touch response, while overall motor behavior stayed unchanged. However, corrective paw placement notably deteriorated, indicating the importance of cutaneous feedback for corrective movements. Similarly Bui et al. [21] showed another interneuron type, dl3, to contribute to grasping. These interneurons receive low threshold mechanosensitive inputs and their ablation reduces grasp strength while leaving general motor function intact. This and previous work [23,24] highlights the diversity of sensory interneurons and further studies will likely reveal the function and circuitry of additional classes.

In terms of network dynamics, peripheral proprioceptive feedback originating from muscle activation provides glutamatergic input to sensory interneurons, which can indirectly lead to muscle activation. Such excitatory feedback loops are intrinsically prone to oscillation [25]. Presynaptic inhibition of sensory afferents has been shown to function as a gain control system to prevent these oscillations to occur [26]. Altogether this recent body of work adds to the evidence that proprioceptive feedback strongly shapes locomotion $[20,26,27]$. 


\section{Intraspinal GABAergic sensory neurons}

Since the description of spinal reflexes by Sir Charles Sherrington, mechanosensory feedback was classically thought to originate solely from peripheral sensory afferents projecting to the dorsal spinal cord. Recently, cerebrospinal-fluid contacting neurons (CSF-cNs) have been identified as intraspinal GABAergic sensory neurons in the ventral spinal cord. Even though initially described nearly a century ago in over vertebrate 200 species [28,29], the function of CSF-cNs is still poorly understood. Searching for the sour taste receptor in the mouse tongue, Huang et al. first described the expression of the TRP channel PKD2L1 in spinal CSF-CNs [30]. Recent detailed molecular characterization established CSF-cNs as coexpressing GABA and PKD2L1 in the spinal cord of zebrafish, mouse and monkey [31,32]. CSF-cNs originate from two distinct progenitor domains in both mouse and zebrafish, suggesting functionally different subpopulations [33-36].

Based on the observation that PKD2L1 is specific to $\mathrm{pH}$ sensitive taste cells in the mouse tongue [37], Huang et al. showed increased firing rates when subjecting PKD2L1 expressing CSF-cNs to low pH in vitro [30]. More detailed pharmacological analysis in the mouse dorsovagal complex and the lamprey spinal cord led to the conclusion that acidification actually inhibits PKD2L1 and likely activates ASIC channels [38,39]. This is in accordance with later studies showing that CSF-cNs do not exhibit a proton current after acidification and activation by low pH is most likely due to ASICs [40]. PKD2L1 is instead activated by alkalization as well as hypo-osmotic shocks [38]. Recent work showed that PKD2L1 likely acts as a spike generator in CSF-CNs and that there is a bimodal response of CSF-CNs [41]. This study and following work in lamprey [42], suggests that firing is increased by alkalization through the activation of PKD2L1 and by acidification through the activation of ASIC channels.

The initial in vitro studies showed that CSF-cNs are sensitive to changes of $\mathrm{pH}$ and osmolarity. Recent work identified mechanosensitive function of CSF-cNs in vitro [39] and in vivo [43]. In the lamprey spinal cord, CSF-cNs show mechanically-evoked firing [39], suggesting these cells may respond to CSF flow. However, from the in vitro studies in mouse and lamprey the relevance of this sensory response for behavior remains unclear. In zebrafish larvae, we showed that CSF-cNs are not recruited during fictive locomotion when muscle contraction does not occur [43]. In contrast, CSF-cNs respond to passive spinal cord bending as well as active muscle contraction. As CSF-cN activation is selective to the side of contraction, the mechanisms by which CSF flow activate CSF-cNs asymmetrically are unclear. Optogenetic 
stimulation of CSF-cNs in zebrafish indicated that these cells can modulate the occurrence and duration of locomotion by connecting to ventro-lateral premotor glutamatergic interneurons $[44,45]$. Furthermore, impairing sensory function or vesicular release in CSF-cNs resulted in a decreased tail-beat frequency [43] in freely-swimming zebrafish larvae, indicating that this mechanosensory feedback shapes active locomotion. In mammals, the connectivity and physiological relevance of intraspinal CSF-cNs remain to be investigated.

\section{Conclusion and perspectives}

By combining genetics, viral tracing and calcium imaging, the work discussed above reveals how genetically identified sensory pathways feedback onto microcircuits in the spinal cord and shape motor output. Segregated sensory feedback from DRGs is integrated by different subtypes of interneurons, which form an overlapping network to generate the segregated output underlying muscle activation $[46,47]$.

While the different types of sensory afferents reaching the spinal cord have been known for a long time, the investigation of intraspinal GABAergic sensory cells and their corresponding sensory stimuli will likely add complexity to the picture. Changes in $\mathrm{pH}$ could be an important signal for spinal cord circuits but to what extend $\mathrm{pH}$ varies in the CSF has not yet been extensively measured under physiological conditions. Mechanical feedback from spinal bending can provide important information during locomotion in aquatic animals such as zebrafish and lamprey. However, to what extend spinal bending happens in mouse spinal cord and whether activation of CSF-cNs plays a role in quadruped locomotion remains to be investigated.

Over the recent years, proprioceptive feedback emerged as a focus of research in the field of spinal cord injury. Significant efforts are put into promoting axonal regeneration across the lesion to regain lost drive to spinal circuits. Yet, it has long been recognized that simple training can improve locomotor deficits after spinal cord lesion [48]. This observation has led to the use of epidural stimulation to activate sensory motor reflex circuits to provide the necessary excitation to initiate locomotion in cats and rats $[49,50]$. These initial findings were followed by epidural stimulations combined with locomotor training in patients with spinal cord injury [5153]. Improvements to this method were recently achieved in rats by using epidural stimulation in a closed loop system where the stimulation protocol was adapted to the leg position in real time [54] and optimized with computational modeling [55]. 
As promising as these results are, epidural stimulation remains a relatively crude method and the underlying mechanisms are poorly understood. Continuing efforts in understanding the role of sensory feedback and signal processing in the spinal cord will not only advance our basic understanding of spinal microcircuit computation but should have very direct effects in the treatment of human spinal cord injury in the future.

\section{Acknowledgements}

U.L.B received support from the École des Neurosciences de Paris lle-de-France (ENP) and the Fondation pour la Recherche Médicale (FRM). This work received support from the Fondation Bettencourt-Schueller, the City of Paris Emergence program, the Atip/Avenir program from CNRS and Inserm, Marie Curie Actions (International Reintegration Grant, IRG \#227200), the ERC Starting Grant Optoloco (\#311673).

\section{References}

1. Grillner S, Jessell TM: Measured motion: searching for simplicity in spinal locomotor networks. Curr. Opin. Neurobiol. 2009, 19:572-586.

2. Delcomyn F: Neural basis of rhythmic behavior in animals. Science 1980, 210:492498.

3. Lundberg A: Multisensory control of spinal reflex pathways. Prog. Brain Res. 1979, 50:11-28.

4. Schomburg ED, Petersen N, Barajon I, Hultborn H: Flexor reflex afferents reset the step cycle during fictive locomotion in the cat. Exp. Brain Res. 1998, 122:339-350.

5. Le Pichon CE, Chesler AT: The functional and anatomical dissection of somatosensory subpopulations using mouse genetics. Front. Neuroanat. 2014, 8:21.

6. Arber S, Ladle DR, Lin JH, Frank E, Jessell TM: ETS Gene Er81 Controls the Formation of Functional Connections between Group la Sensory Afferents and Motor Neurons. Cell 2000, 101:485-498.

7. de Nooij JC, Doobar S, Jessell TM: Etv1 inactivation reveals proprioceptor subclasses that reflect the level of NT3 expression in muscle targets. Neuron 2013, 77:10551068.

8. Usoskin D, Furlan A, Islam S, Abdo H, Lönnerberg P, Lou D, Hjerling-Leffler J, Haeggström J, Kharchenko O, Kharchenko PV, et al.: Unbiased classification of sensory neuron types by large-scale single-cell RNA sequencing. Nat. Neurosci. 2015, 18:145-153. 
${ }^{* * 9}$. Li C-L, Li K-C, Wu D, Chen Y, Luo H, Zhao J-R, Wang S-S, Sun M-M, Lu Y-J, Zhong Y-Q, et al.: Somatosensory neuron types identified by high-coverage single-cell RNAsequencing and functional heterogeneity. Cell Res. 2016, 26:83-102. This study uses single cell RNA sequencing to tackle the question of how to define a DRG neuron subtype. The authors define 14 subclasses of DRG neurons based on clustering of gene expression data and validate their functional heterogeneity with patch-clamp recordings.

10. Coste B, Mathur J, Schmidt M, Earley TJ, Ranade S, Petrus MJ, Dubin AE, Patapoutian A: Piezo1 and Piezo2 Are Essential Components of Distinct Mechanically Activated Cation Channels. Science 2010, 330:55-60.

11. Faucherre A, Nargeot J, Mangoni ME, Jopling C: piezo2b Regulates Vertebrate Light Touch Response. J. Neurosci. 2013, 33:17089-17094.

12. Ikeda R, Cha M, Ling J, Jia Z, Coyle D, Gu JG: Merkel cells transduce and encode tactile stimuli to drive A $\beta$-afferent impulses. Cell 2014, 157:664-675.

13. Maksimovic S, Nakatani M, Baba $Y$, Nelson AM, Marshall KL, Wellnitz SA, Firozi P, Woo $\mathrm{S}-\mathrm{H}$, Ranade S, Patapoutian A, et al.: Epidermal Merkel cells are mechanosensory cells that tune mammalian touch receptors. Nature 2014, 509:617-621.

14. Woo S-H, Ranade S, Weyer AD, Dubin AE, Baba Y, Qiu Z, Petrus M, Miyamoto T, Reddy $\mathrm{K}$, Lumpkin EA, et al.: Piezo2 is required for Merkel-cell mechanotransduction. Nature 2014, 509:622-626.

*15. Ranade SS, Woo S-H, Dubin AE, Moshourab RA, Wetzel C, Petrus M, Mathur J, Bégay V, Coste B, Mainquist $\mathrm{J}$, et al.: Piezo2 is the major transducer of mechanical forces for touch sensation in mice. Nature 2014, 516:121-125. This study is the last in a list that puts Piezo2 in the center of touch sensation in vertebrates. Eliminating Piezo2 from Merkel cells and sensory neurons lead to an almost complete loss of touch sensitivity.

**16. Woo S-H, Lukacs V, de Nooij JC, Zaytseva D, Criddle CR, Francisco A, Jessell TM, Wilkinson KA, Patapoutian A: Piezo2 is the principal mechanotransduction channel for proprioception. Nat. Neurosci. 2015, 18:1756-1762. Using mouse conditional knockout lines for Piezo2, the authors of this study show that Piezo2 is the main channel for proprioception. Piezo2 deficient DRG neurons lost most of their mechanically induced currents and consequently Piezo2 conditional knockout mice had severe limb coordination deficits.

17. Vrontou S, Wong AM, Rau KK, Koerber HR, Anderson DJ: Genetic identification of C fibres that detect massage-like stroking of hairy skin in vivo. Nature 2013, 493:669673.

18. Poole K, Herget R, Lapatsina L, Ngo H-D, Lewin GR: Tuning Piezo ion channels to detect molecular-scale movements relevant for fine touch. Nat. Commun. 2014, 5:3520.

19. McCrea DA, Rybak IA: Organization of mammalian locomotor rhythm and pattern generation. Brain Res. Rev. 2008, 57:134-146. 
**20. Akay T, Tourtellotte WG, Arber S, Jessell TM: Degradation of mouse locomotor pattern in the absence of proprioceptive sensory feedback. Proc. Natl. Acad. Sci. U. S. A. 2014, 111:16877-16882. Using a mutant mouse model that lacks functional muscle spindles the authors address the question of how proprioceptive feedback shapes locomotion. Their study shows that loss of proprioception from muscle spindles leads to specific degradation of mouse walking. Missing muscle spindle feedback during walking is probably compensated by GTO feedback since swimming mice where GTO load is reduced show a more severe phenotype.

21. Bui TV, Akay T, Loubani O, Hnasko TS, Jessell TM, Brownstone RM: Circuits for grasping: spinal dl3 interneurons mediate cutaneous control of motor behavior. Neuron 2013, 78:191-204.

*22. Bourane S, Grossmann KS, Britz O, Dalet A, Del Barrio MG, Stam FJ, Garcia-Campmany L, Koch S, Goulding M: Identification of a Spinal Circuit for Light Touch and Fine Motor Control. Cell 2015, 160:503-515. This study identifies ROR alpha positive interneurons as a central element in a pathway integrating light touch response and supraspinal input. This elegant study also shows the importance of cutaneous input for corrective movements during walking on uneven terrain.

23. Betley JN, Wright CVE, Kawaguchi Y, Erdélyi F, Szabó G, Jessell TM, Kaltschmidt JA: Stringent Specificity in the Construction of a GABAergic Presynaptic Inhibitory Circuit. Cell 2009, 139:161-174.

24. Hantman AW, Jessell TM: Clarke's column neurons as the focus of a corticospinal corollary circuit. Nat. Neurosci. 2010, 13:1233-1239.

25. Stein RB, Oğuztöreli MN: Tremor and other oscillations in neuromuscular systems. Biol. Cybern. 1976, 22:147-157.

*26. Fink AJP, Croce KR, Huang ZJ, Abbott LF, Jessell TM, Azim E: Presynaptic inhibition of spinal sensory feedback ensures smooth movement. Nature 2014, 509:43-48. This study highlights the importance of inhibitory feedback in the control of motion. To prevent oscillation, presynaptic inhibition is shown to play a central role in controling gain in goaldirected forelimb movements. The authors nicely support their findings by reproducing them in a computational model.

27. Williams $R$, Hale ME: Fin ray sensation participates in the generation of normal fin movement in the hovering behavior of the bluegill sunfish (Lepomis macrochirus). J. Exp. Biol. 2015, 218:3435-3447.

28. Agduhr E: Über ein zentrales Sinnesorgan bei den Vertebraten. $Z$ Anat EntwGesch 1922, [no volume].

29. Kolmer W: Das 'Sagitallorgan der Wirbeltiere. Z Anat EntwGesch 1921, [no volume].

30. Huang AL, Chen X, Hoon MA, Chandrashekar J, Guo W, Tränkner D, Ryba NJP, Zuker CS: The cells and logic for mammalian sour taste detection. Nature 2006, 442:934938. 
*31. Djenoune L, Khabou H, Joubert F, Quan FB, Nunes Figueiredo S, Bodineau L, Del Bene $\mathrm{F}$, Burcklé $\mathrm{C}$, Tostivint $\mathrm{H}$, Wyart $\mathrm{C}$ : Investigation of spinal cerebrospinal fluidcontacting neurons expressing PKD2L1: evidence for a conserved system from fish to primates. Front. Neuroanat. 2014, 8:26. This cross-species study establishes PKD2L1 as a marker for CSF-cNs across vertebrates and shows that CSF-cNs share the same markers and morphology in zebrafish, mouse, and macaque.

32. Orts-Del'Immagine A, Kastner A, Tillement V, Tardivel C, Trouslard J, Wanaverbecq N: Morphology, distribution and phenotype of polycystin kidney disease 2-like 1positive cerebrospinal fluid contacting neurons in the brainstem of adult mice. PloS One 2014, 9:e87748.

*33. Petracca YL, Sartoretti MM, Di Bella DJ, Marin-Burgin A, Carcagno AL, Schinder AF, Lanuza GM: The late and dual origin of cerebrospinal fluid-contacting neurons in the mouse spinal cord. Dev. Camb. Engl. 2016, 143:880-891. This elegant study explores the developmental origins of CSF-cNs in mouse and demonstrates the differential origin of CSF-cNs as in zebrafish while also highlighting developmental differences between the species.

34. Park H-C, Shin J, Appel B: Spatial and temporal regulation of ventral spinal cord precursor specification by Hedgehog signaling. Development 2004, 131:5959-5969.

35. Huang P, Xiong F, Megason SG, Schier AF: Attenuation of Notch and Hedgehog signaling is required for fate specification in the spinal cord. PLoS Genet. 2012, 8:e1002762.

36. Yang L, Rastegar S, Strähle U: Regulatory interactions specifying Kolmer-Agduhr interneurons. Development 2010, 137:2713-2722.

37. Ishimaru $Y$, Inada $H$, Kubota $M$, Zhuang $H$, Tominaga $M$, Matsunami $H$ : Transient receptor potential family members PKD1L3 and PKD2L1 form a candidate sour taste receptor. Proc. Natl. Acad. Sci. U. S. A. 2006, 103:12569-12574.

38. Orts Del'immagine A, Wanaverbecq N, Tardivel C, Tillement V, Dallaporta M, Trouslard J: Properties of subependymal cerebrospinal fluid contacting neurones in the dorsal vagal complex of the mouse brainstem. J. Physiol. 2012, doi:10.1113/jphysiol.2012.227959.

**39. Jalalvand E, Robertson B, Wallén P, Grillner S: Ciliated neurons lining the central canal sense both fluid movement and pH through ASIC3. Nat. Commun. 2016, 7:10002. Using the lamprey spinal cord as an in vitro model system, this study shows a dual response of CSF-cNs to mechanical stimulation and changes in $\mathrm{pH}$.

40. Bushman JD, Ye W, Liman ER: A proton current associated with sour taste: distribution and functional properties. FASEB J. Off. Publ. Fed. Am. Soc. Exp. Biol. 2015, doi:10.1096/fj.14-265694.

41. Orts Del'Immagine A, Seddik R, Tell F, Airault C, Er-Raoui G, Najimi M, Trouslard J, Wanaverbecq N: A single polycystic kidney disease 2-like 1 channel opening acts as a spike generator in cerebrospinal fluid-contacting neurons of adult mouse brainstem. Neuropharmacology 2015, doi:10.1016/j.neuropharm.2015.07.030. 
42. Jalalvand $E$, Robertson $B$, Tostivint $H$, Wallén $P$, Grillner S: The Spinal Cord Has an Intrinsic System for the Control of pH. Curr. Biol. 2016, doi:10.1016/j.cub.2016.03.048.

**43. Böhm UL, Prendergast A, Djenoune L, Nunes Figueiredo S, Gomez J, Stokes C, Kaiser S, Suster M, Kawakami K, Charpentier M, et al.: CSF-contacting neurons regulate locomotion by relaying mechanical stimuli to spinal circuits. Nat. Commun. 2016, 7:10866. Using a combination of calcium imaging, genetics and behavior analysis, this study links CSF-cNs to mechanosensation in vivo. The study also shows behavioral deficits in zebrafish larvae either missing PKD2L1 or impaired vesicular release.

44. Wyart C, Del Bene F, Warp E, Scott EK, Trauner D, Baier H, Isacoff EY: Optogenetic dissection of a behavioural module in the vertebrate spinal cord. Nature 2009, 461:407-410.

*45. Fidelin K, Djenoune L, Stokes C, Prendergast A, Gomez J, Baradel A, Del Bene F, Wyart C: State-Dependent Modulation of Locomotion by GABAergic Spinal Sensory Neurons. Curr. Biol. CB 2015, 25:3035-3047. Using optogenetic activation of cerebrospinal fluid-contacting neurons, this study investigates their modulatory role and connectivity in zebrafish spinal cord. Interestingly the inhibitory feedback of CSF-cNs lead to a modulation of frequency and duration of locomotor events depending on the excitatory state of the spinal cord.

46. Ma Q: Population coding of somatic sensations. Neurosci. Bull. 2012, 28:91-99.

47. Bui TV, Stifani N, Panek I, Farah C: Genetically identified spinal interneurons integrating tactile afferents for motor control. J. Neurophysiol. 2015, 114:3050-3063.

48. Rossignol S, Martinez M, Escalona M, Kundu A, Delivet-Mongrain H, Alluin O, Gossard J$P$ : Chapter 8 - The "beneficial" effects of locomotor training after various types of spinal lesions in cats and rats. In Progress in Brain Research. Edited by Numa Dancause SN and SR. Elsevier; 2015:173-198.

49. Gerasimenko YP, Avelev VD, Nikitin OA, Lavrov IA: Initiation of Locomotor Activity in Spinal Cats by Epidural Stimulation of the Spinal Cord. Neurosci. Behav. Physiol. 2003, 33:247-254.

50. Ichiyama RM, Gerasimenko YP, Zhong H, Roy RR, Edgerton VR: Hindlimb stepping movements in complete spinal rats induced by epidural spinal cord stimulation. Neurosci. Lett. 2005, 383:339-344.

51. Harkema S, Gerasimenko Y, Hodes J, Burdick J, Angeli C, Chen Y, Ferreira C, Willhite A, Rejc E, Grossman RG, et al.: Effect of Epidural stimulation of the lumbosacral spinal cord on voluntary movement, standing, and assisted stepping after motor complete paraplegia: a case study. Lancet 2011, 377:1938-1947.

52. Angeli CA, Edgerton VR, Gerasimenko YP, Harkema SJ: Altering spinal cord excitability enables voluntary movements after chronic complete paralysis in humans. Brain J. Neurol. 2014, 137:1394-1409. 
53. Hofstoetter US, Danner SM, Freundl B, Binder H, Mayr W, Rattay F, Minassian K: Periodic modulation of repetitively elicited monosynaptic reflexes of the human lumbosacral spinal cord. J. Neurophysiol. 2015, 114:400-410.

*54. Wenger N, Moraud EM, Raspopovic S, Bonizzato M, DiGiovanna J, Musienko P, Morari M, Micera S, Courtine G: Closed-loop neuromodulation of spinal sensorimotor circuits controls refined locomotion after complete spinal cord injury. Sci. Transl. Med. 2014, 6:255ra133. This study uses a closed-loop system to modulate epidural stimulation as a function of limb position. This feedback system led to marked improvements in motor control in spinalized rats.

55. Moraud EM, Capogrosso M, Formento E, Wenger N, DiGiovanna J, Courtine G, Micera S: Mechanisms Underlying the Neuromodulation of Spinal Circuits for Correcting Gait and Balance Deficits after Spinal Cord Injury. Neuron 2016, 89:814-828.

\section{Figure legends}

\section{Figure 1}

Sensory feedback circuits in the spinal cord. Peripheral sensory information is carried by dorsal root ganglion (DRG) neurons and provides excitatory input either directly to motor neurons (MNs) or to the spinal interneuron (IN) network. External inputs include the sensation of temperature, pain, itch and chemical irritants as well as mechanical touch. Internal peripheral sensation comes from mechansosensitive inputs from muscle spindles and Golgi tendon organ (GTO). Inside the spinal cord, inhibitory feedback from cerebrospinal fluid-contacting neurons (CSF-cNs) carry information about the bending of the spinal cord as well as $\mathrm{pH}$ and osmolarity of the cerebrospinal fluid (CSF). The IN network integrates peripheral and intraspinal sensory inputs as well as supras pinal commands and provides patterned inhibition and excitation that ultimately lead to rhythmic MN activation. 